\title{
POLY CHORDS AND USE IN SOLFEGE
}

Fatima Mahmoud AL-JARASHA *

Faculty of Music Education, Helwan University, Egypt

\section{Abstract}

The harmony is several tones that can be heard at the same time, which is either a triple of all kinds $(k, p, g, n)$ in its basic position or with its different upheavals, and a quadruple with its five types, as Dalcruz struck it, all of these contortions are heard individually until the master's stage, the doctoral stage comes the student listens To pluralism.

Keywords

Poly Chords, Solfege, Music, Education.

\section{Introduction}

The harmony is several tones that can be heard at the same time, which is either a triple of all kinds $(\mathrm{k}, \mathrm{p}, \mathrm{g}, \mathrm{n})$ in its basic position or with its different upheavals, and a quadruple with its five types, as Dalcruz struck it, all of these contortions are heard individually until the master's stage. To pluralism in:

A- The multiplicity of the stairs: Poly Tonality means playing two stairs at the same time, whether they are similar in color or different $(\mathrm{k}, \mathrm{p})$, and their performance may be in playing either in one direction while playing or in different directions.

B- Poly modality: which is playing two different maqamat simultaneously with the same previous performance.

C- Poly Chords: Hearing more than two harmonic combinations at the same time, similar or different in color on different degrees and areas of sound, which increase in their resonance the intensity of tension and excitement, and have many forms and configurations that may appear with the presence of two types of synergies. The three (n, y, g, n).

And when mentioning all kinds of harmonic defects, it is necessary to mention the harmonic chain that follows the harmonic damage "Overtones:"

D- The harmonic string "Overtones": it is called the harmonic string accompanying the base tone (Harmonic Series) or accompanying any tone played on the bus, resulting in sixteen graces, which is known as the harmonic string harmonics.

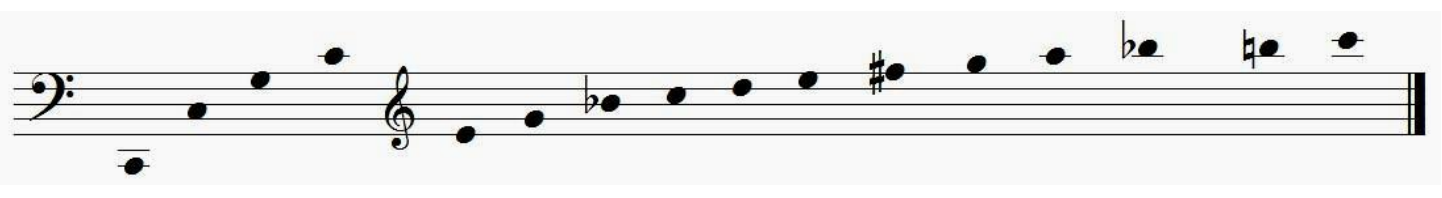

* Corresponding author: info@music.helwan.edu.eg 


\section{Uses of poly chords:}

The onset of multiple rotations is shown by the birds of extended notes (Pedal Notes) as in the following example:

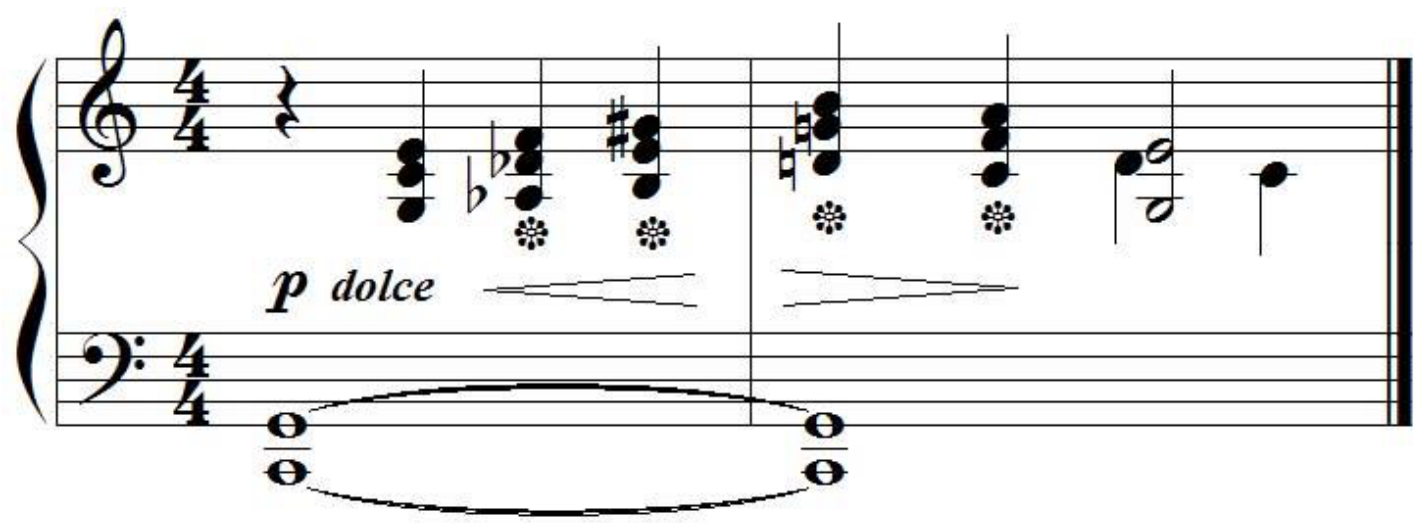

By analyzing the first match, we find the synergies (courses), then (t, you), then (Mick) in the second cabinet a co-ordination ( $\mathrm{sol} / \mathrm{a})$ then $(\mathrm{fa} \mid)$ then $(\mathrm{du} /$ )

Hear all these chords simultaneously with the paddle note in the bass. And the harmonic harmonic multiple (Poly Chords) appear in separate scales as in the form of a number ():

The harmony (ry / k) in the upper sound and the harmony (fa / k) in the lower one.

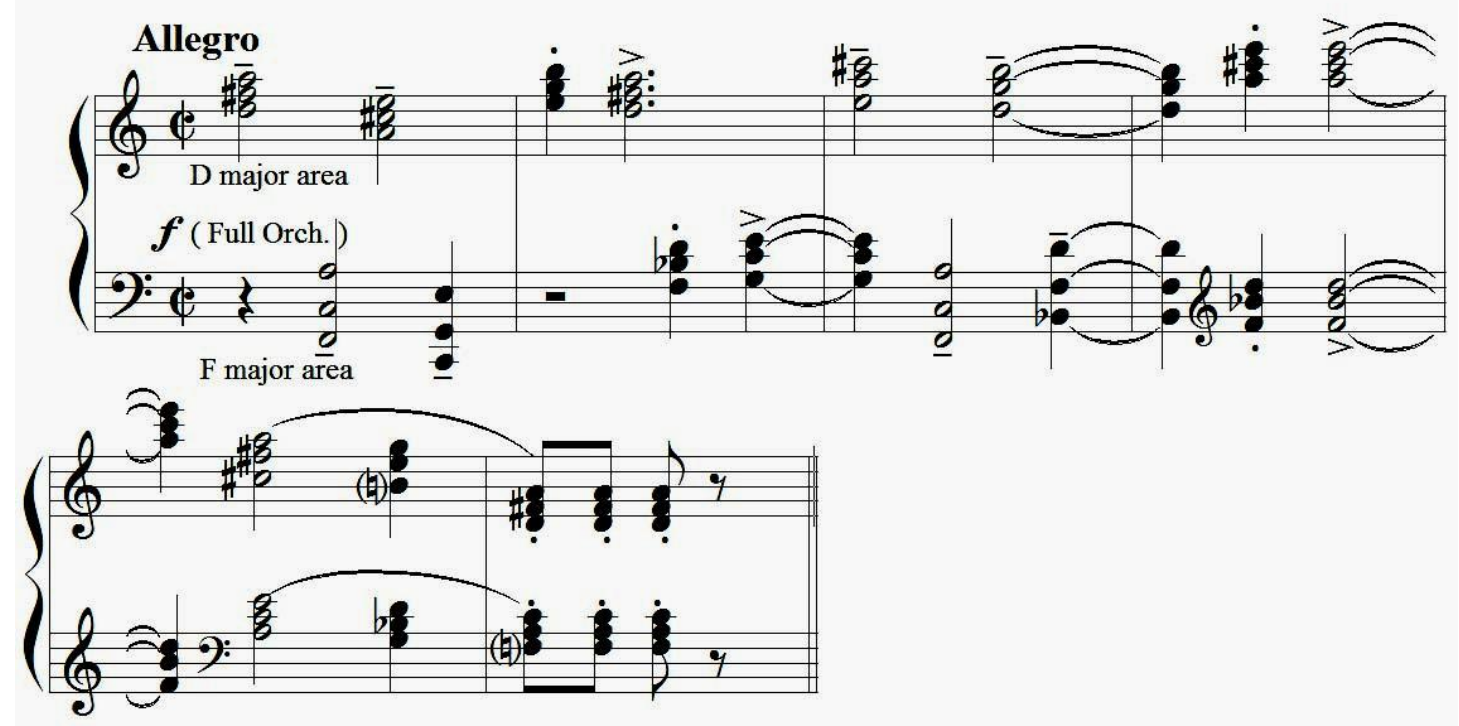

In addition, there are multiple compositions that are suitable for use in musical stories, which are severely dissonant in their composition. Often the multiple harmonic combinations are not proven in one form, as in Figure 4: 


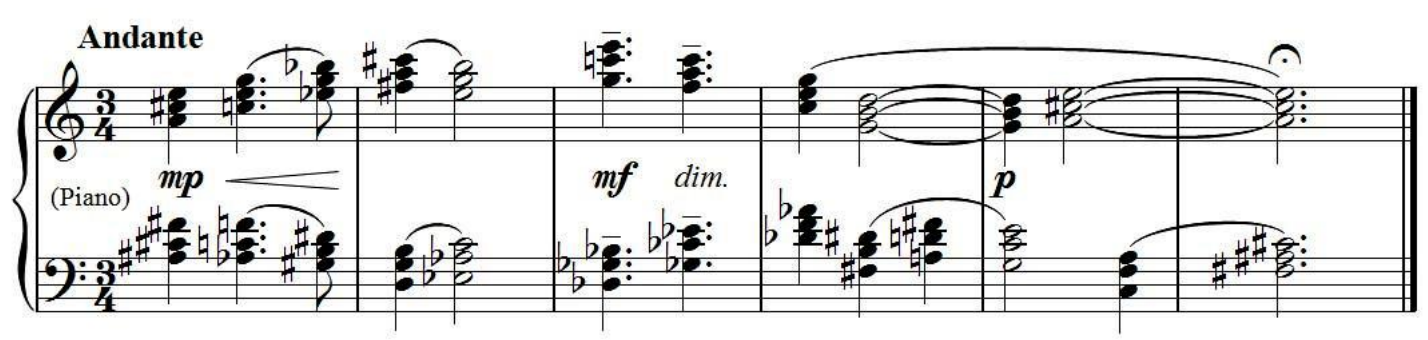

Multiple harmonic twists can be poly chords in a sequence (from a complete fifth circle that starts on the bass tone of the great inverted symphysis a second heart, as in Figure 5):

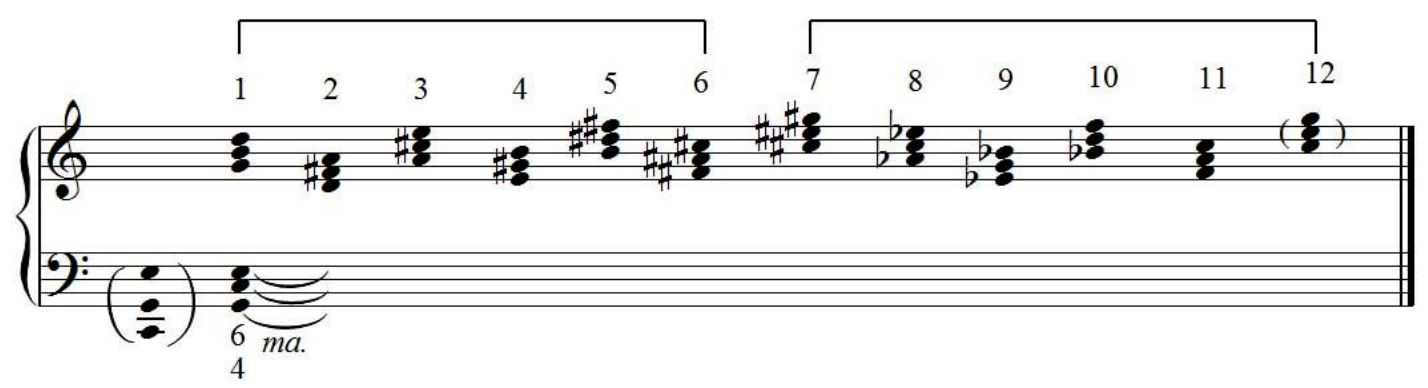

It is possible to construct harmonic synergies in a complete fifth circle sequence with building a small harmonic in the bus, as in Figure (6):

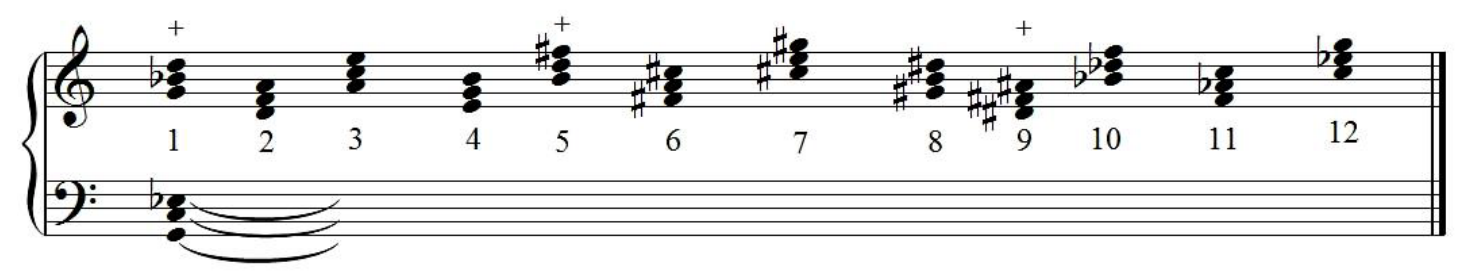

Poly-chords can be constructed by creating small spoilages that are heard simultaneously with large combinations at different concentrations of degrees, as in Figure (7):

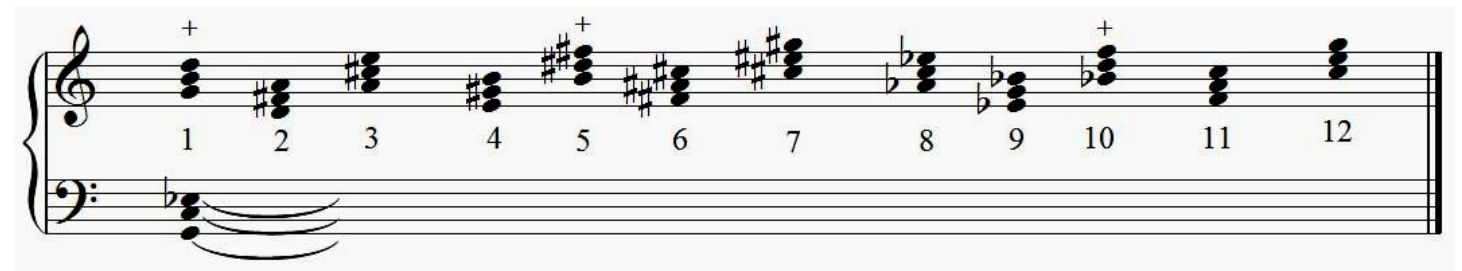

Poly chords move in a harmonious movement up, so their resonance decreases as indicated in figure () in the parallel bars $(1,2)$, and when they move in a harmonic movement downward, violence and roughness appear as in the synthesizer $(3,4)$ :

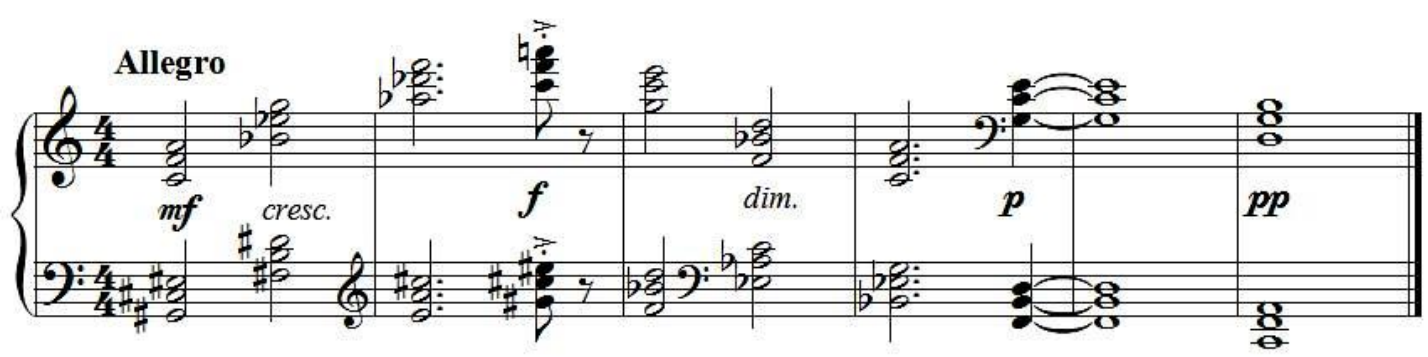


All the various combinations often include one of excess or missing damages, as shown in Figure 9:

(1)

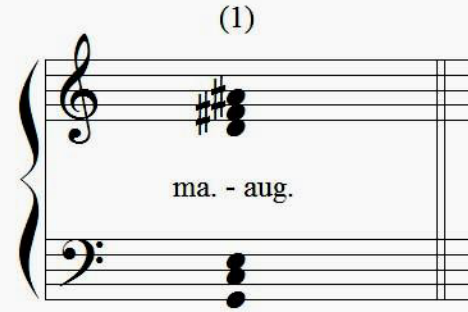

(2)

(3)

(4)

When using the syllable plus or the decrease in the lower sounds, it is preferable to use them at separate distances, as in Figure 10:
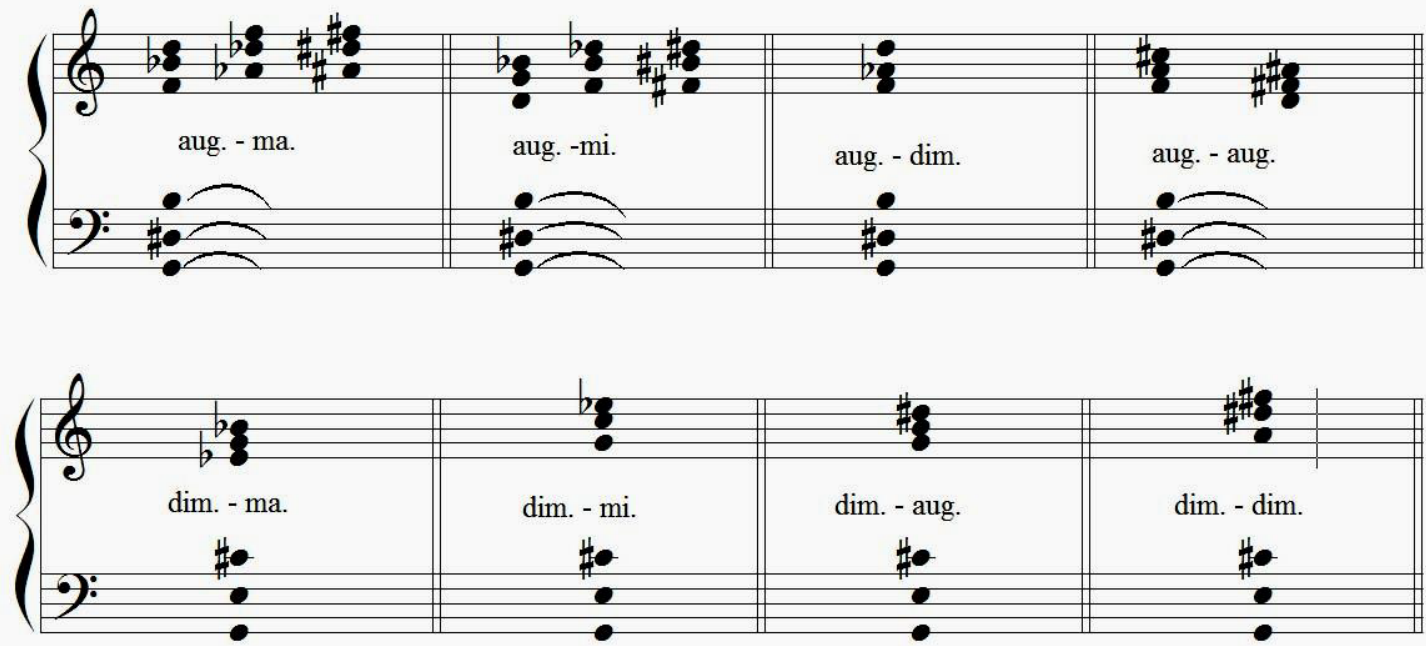

Multiple harmonic chords can be based on different melodic degrees of the harmonic string "Overtone" or other degrees derived from the degrees of this harmonic chain. There are also four types of multiple harmonic formations as follows:

- The first configuration: Harmonic chords are based on the third or fifth base tone, as in Figure 11:

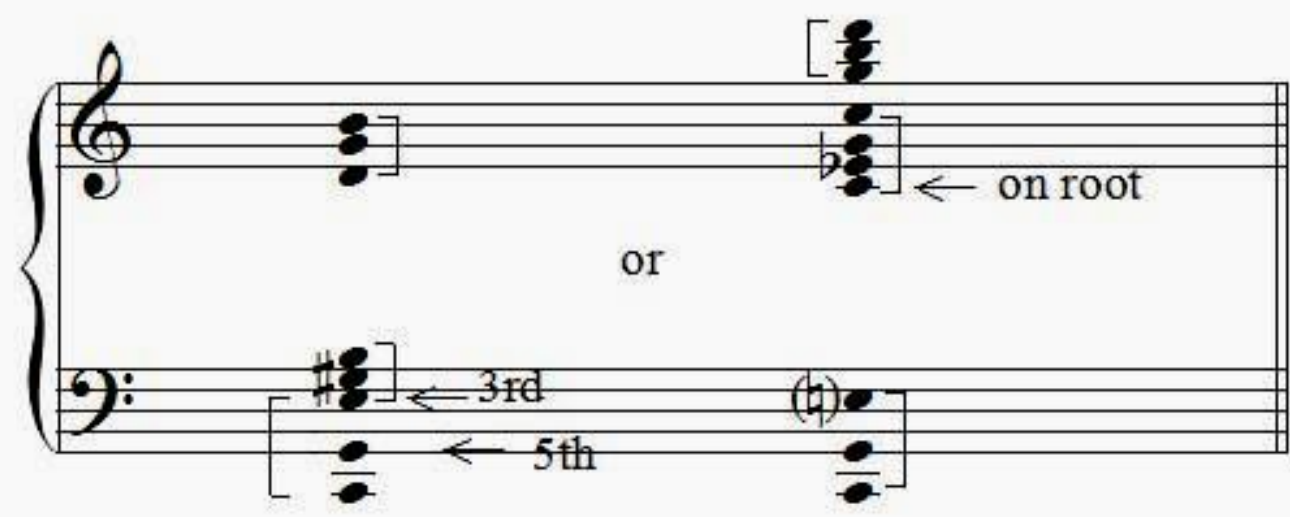


- The second configuration: the harmony is based on the fifth grade of the bass tone (C), as well as the fifth tone of the bass (Ray), as in Figure (12):

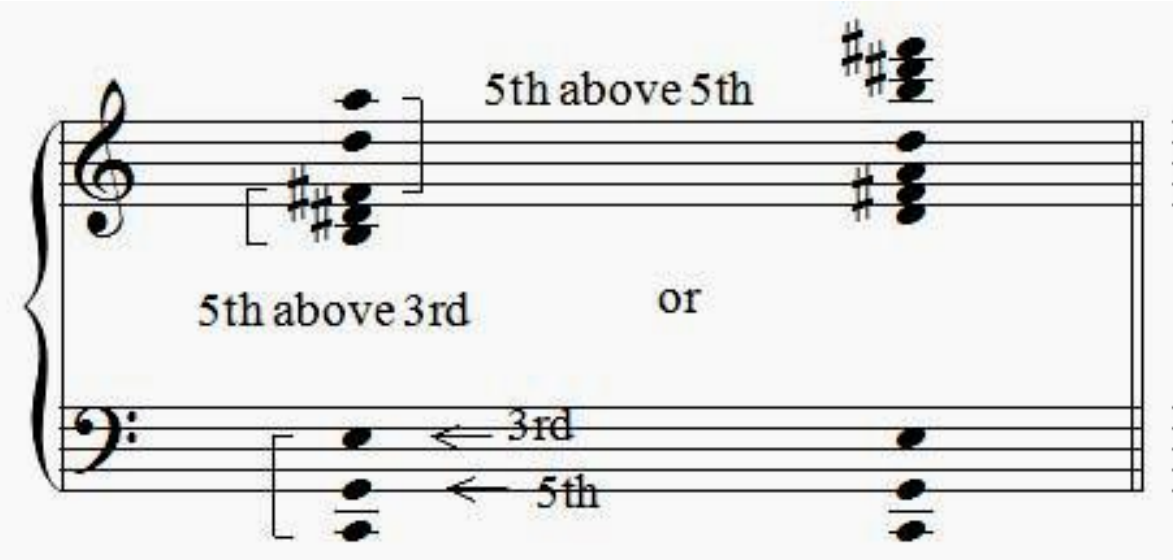

- The third composition: In it, harmonic syntheses are based on the fifth of the third degree of the bass tone, as well as the fifth on the fifth for the bass tone (no), as in Figure (13):

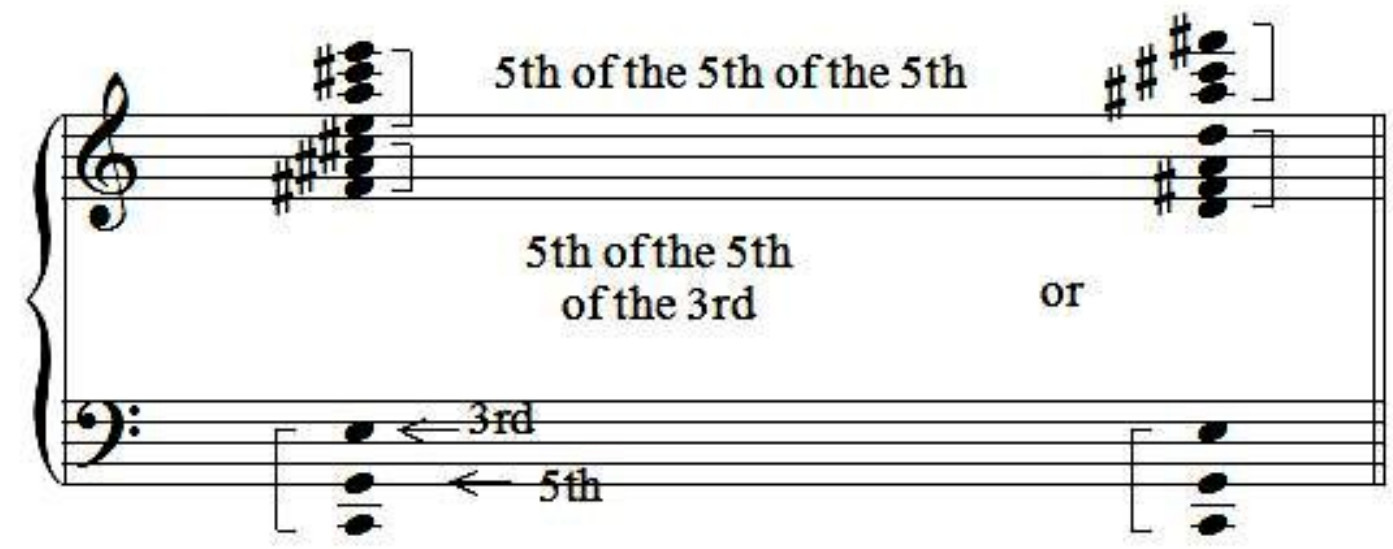

- The fourth formation: the multiple harmonic combinations are based on the third base of the harmonic chain (Me), then on the third large of the third base (Sol \#) and then on the fifth third base (Ray \#) as in Figure No. (14) so that the multiple and audible combinations together are ( (Dou / k + m / k + r\# / r + ry \#/k). 


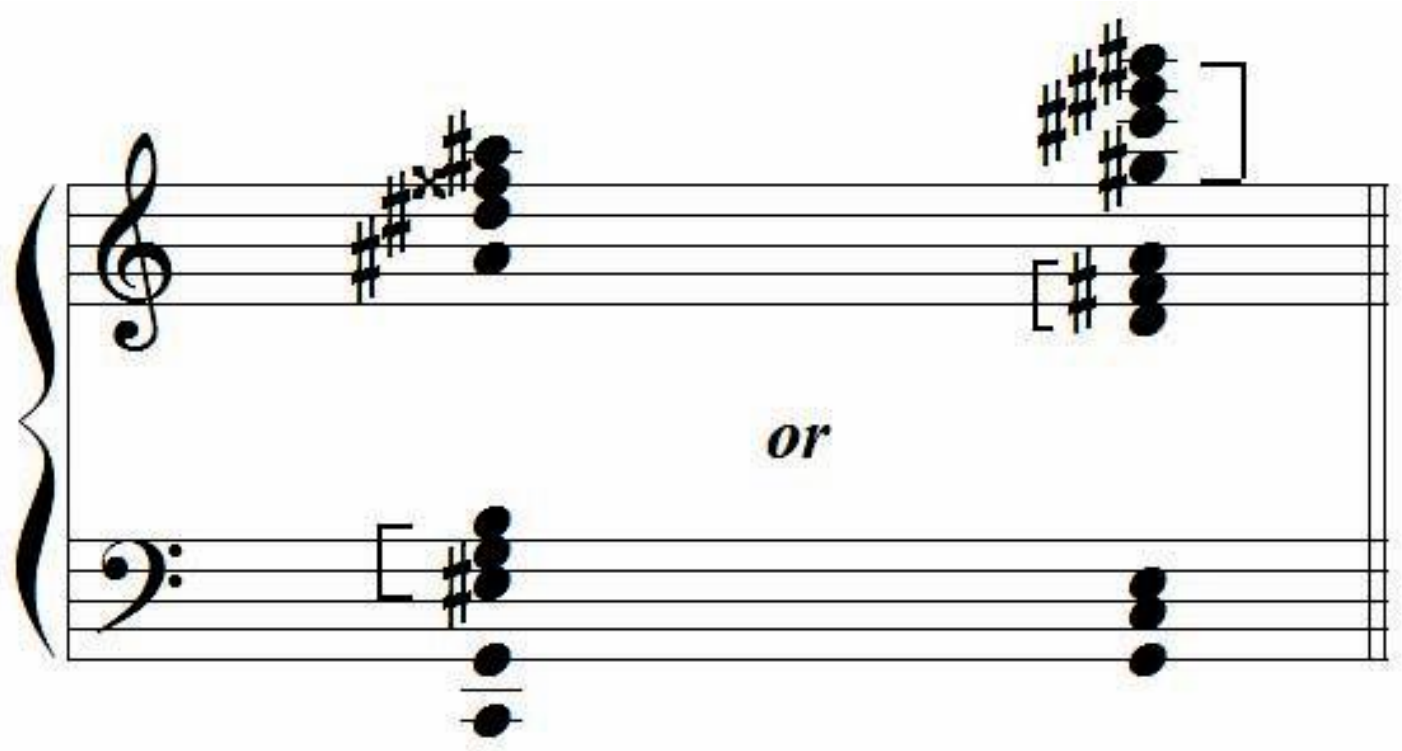

- Multiple harmonic combinations appear in more than two combinations heard together giving a dense harmonious texture as in figure (15):

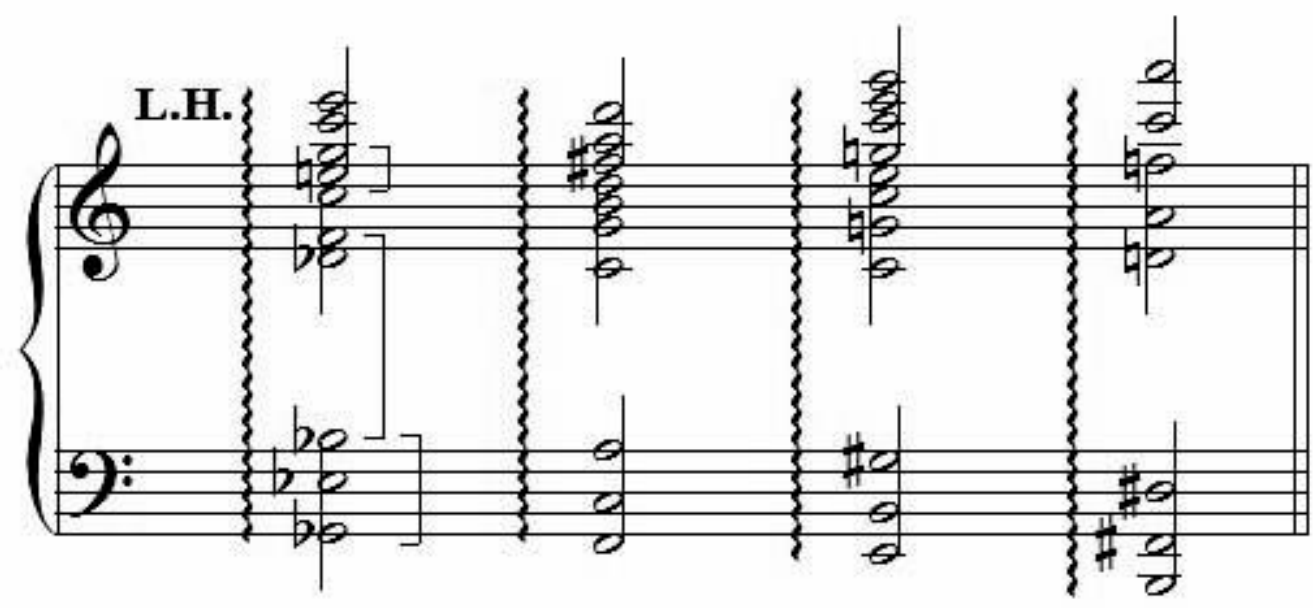

The previous figure shows the use of multiple harmonic combinations in two groups of harmonics, the first $(\mathrm{Me} / \mathrm{Y})$ and then the $(\mathrm{R} / \mathrm{G})$ combination to show the (Do / K) combination.

Harmonic chords evolved until the differences between harmonious and dissonant chords were eliminated, so the music moved from discordant harmonies to more discordant harmonies, and the types of double or compound harmonies also appeared, which means the emergence of different types of harmonies at the same time: 


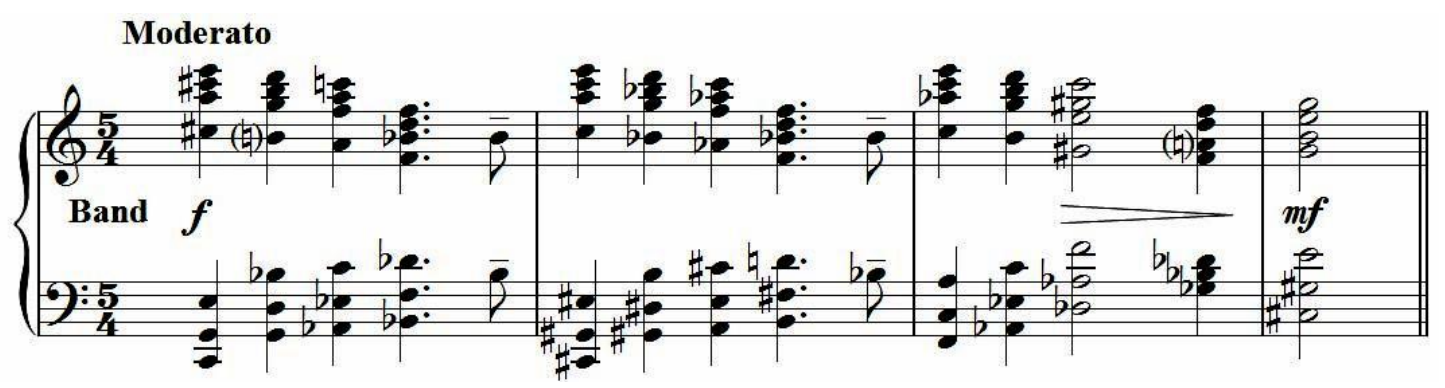

\section{References}

1- Awatef Abdel Karim and others: Muhit al-Funun, the musician, Cairo: Dar Al-Maarif, 190, p. 21.

2- Greet Britain-wm. Collins Sons \& Co. Ltd. 1984. p. 213.

3- Persiehetti, Vincent Twentieth Century Harmony Creative A spects and Practice, U.S.A. Vol 1, Ballou Press, Inc. 1967. P. 139.

4- Westrup. Jack and F. Li Harrison Collins pocket Dictionary of music.

5- Nashwa Mustafa NAGY, DEVELOPMENT OR ADVANCEMENT OF HANDMADE TEXTILES AS A CRAFT AND ITS ROLE IN DEVELOPING THE ENVIRONMENT OR SOCIETY OR TO PRESERVE THE CULTURAL AND ARTISTIC EGYPTIAN IDENTITY AND REDUCE THE UNEMPLOYMENT RATE AMONG YOUTH, International Journal of Humanities and Language Research, Vol. 1, No. 1, 2018, pp. 33-37.

Received: August 2, 2018

Accepted: October 30, 2018 